\title{
SAFETY GUIDE AGAINST LIGHTNING HAZARDS
}

\author{
N. Kitagawa \\ Central Lightning Protection Inc. 1-36-12 Yoyogi, Shibuya-ku, Tokyo 151 \\ M. Ohashi \\ Tokyo Denryoku Hospital, Shinjyuku-ku, Tokyo 160 \\ T. Ishikawa \\ School of Rehabilitation, Tokyo National Chest Hospital, Kiyose-shi 204
}

\begin{abstract}
. 59 lightning accidents of human bodies have been investigated and it is confirmed that death is caused only when the main lightning current flows into human body either by a direct flash or a side flash. The injuries caused on persons situated in the vicinity of struck points, are slight and far from fatal, even if they were sitting or 1ying down on the ground. On the other hand squatting or sitting postures are not safe enough to avoid direct or side flashes. On the basis of these results the authors present practical safety guide against lightning hazards.
\end{abstract}

\section{Introduction}

Concerning death and injuries by lightning, modern knowledge has been considerably accumulated, as represented by Golde and Lee (1976). However, in order to establish the effective safety guide, a studies on electrical nature of lightning on human bodies have to be combined with their medical studies. In 1970 the authors organized a research group consisting of physicists, electrical engineers and physicians. The group carried out numerous lightning-simulating experiments using dolls whose electrical properties are equivalent to human bodies and also using various kinds of animals (Kitagawa et a1., 1985). In parallel with the laboratory studies, the group carried out on-the-spot investigations of lightning accidents and accumulated data for 59 thunderbolts, for recent 20 years. On the basis of these studies, the authors have re-examined the conventional safety guides and present effective and practical guide to avoid lightning hazards.

2. Results of investigation of 59 accidents

The following items were examined by on-the-spot investigations:

(1)The surrounding conditions in which persons were involved in lightning accidents.

(2)The clothes and all other objects which affected persons wore or carried,

Table 1. Classification and number of sufferers

No. of No. of suffered persons

Flashes Dead Severely Slightly

\begin{tabular}{lrrrr}
\hline Direct flash & 36 & 28 & 9 & 27 \\
Side flash & 17 & 14 & 8 & 57 \\
Forked flash & 4 & 7 & 6 & 24 \\
Indoor incidents & 2 & 0 & 0 & 2 \\
\hline Total & 59 & 49 & 23 & 110
\end{tabular}


(3)The physical condition and progress of the affected persons, including results of the examinations and treatments they received at hospitals.

The main results are listed in Table 1. "Side flashes" occurred most1y from trees to adjacent persons and sometimes from poles of tents to persons inside tents. A "Forked flash" means the lightning flash which struck plural points on ground in a course of one flash. The lightning accidents caused on persons inside buildings are classified as "Indoor incidents", the effects of which were found to be very slight.

Those persons who lost their consciousness for more than twenty minutes and were hospitalized for more than several days, are classified as "Severely suffered persons". Other persons in the vicinity of struck points suffered superficial burns, ear ringing, temporal pain or paralysis. Most of them recovered in a few days, while a few of them suffered monthslasting slight pain. As a whole, persons affected in the vicinity of struck points are classified as "Slightly suffered persons". In the case of direct flash accidents, the difference of severe and slight sufferings was quite distinct and no intermediate sufferings were observed.

In case of the direct flashes, each flash caused either one dead person or one severely suffered person. A11 other persons who were closely situated, were suffered only slightly. The results disclose following two noteworthy points:(1) the effective side flash from person to person does not occur and (2) the current flow on ground surface from the struck person does not cause any severe injuries on persons situated closely around him.

Among 17 side flash accidents, two persons resting under trees were killed simultaneously in four cases and one was killed while the other was severely injured in one case. These results indicate that the trees struck by lightning, worked to transfer heavy lightning current almost evenly to the two persons. Because of the occurrence of the above five accidents, the summed number of died and severely injured persons exceeds the number of the flashes.

3. Did victims carry metal pieces or so-called lightning-inducing objects?

For 23 directly struck persons, the authors could ascertain the condiions whether they wore metal pieces around their heads and whether they carried some long objects which would have effectively induced lightning incidence. The results are shown in Table 2 .

Table 2. Conditions of 23 dịrect flash sufferers

14 sufferers carried none.

9 sufferers carried so-called lightning-inducing objects as follows: 2: using umbrellas

1: a raised racket over head,

1: a pin on a raised hand,

1: a hair pin on head,

4: wearing caps with small metal pieces.

The results indicate that metal pieces on human bodies do not exert any 1ightning-inducing effect but the human bodies themselves react to thunderbolts as effective lightning-inducing objects. Peterson (1962) derived the similar conclusion by analyzing the lightning injuries on mountaineers. The authors' laboratory studies (Kitagawa et a1., 1985) also showed that small metal pieces on simulated human bodies exerted no flash-inducing effect while long objects extruding higher than heads, effectively induced flash- 
es, regardless of their conductivity .

4. Did persons severely affected by step voltages?

The following formula is often cited in discussing the injuries caused by step voltages due to close thunderbolts (e.g., Golde and Lee, 1976):

$$
u=i \times(\rho / 2 \pi) \times\{s / d(d+s)\}
$$

where $i$ is the peak lightning current in amperes; $\rho$, the soil resistivity in ohm-meters; $s$, the step length in meters and $d$, the distance between struck point and nearer leg in meters. However, the movement of electric charge on the ground due to the thunderbolt is entirely different from the hemispherically symmetric current distribution which the formula postulates. Moreover, it is occasionally observed that surface flashovers develop on ground surface from the struck point. In this case, current distribution is quit different from one in which current flows solely as conduction current. In any case, the above formula is useless in estimating the electrical effect on human bodies which are situated close to struck points.

The investigated accidents included 38 cases in which plural persons were situated close to struck points. The authors examined the injuries caused on persons who took postures in which step voltages might have affected them. However, none of them were dead or severely suffered. Both dead and severely suffered persons were confined to those who were struck by either direct or side flashes. The rest of persons were only slightly suffered. Two representative cases will be described below.

Fifteen persons engaging in forest work, were resting on a hilly terrain as shown in Fig. 1. Rain started to precipitate but the ground was not wet, while thunder was not audible. Suddenly a thunderbolt struck a central cedar tree, and two women $(a, b)$ sitting at its root, lost their consciousness. A sitting man (h) felt to have his lower limbs numbed and got slight thermal

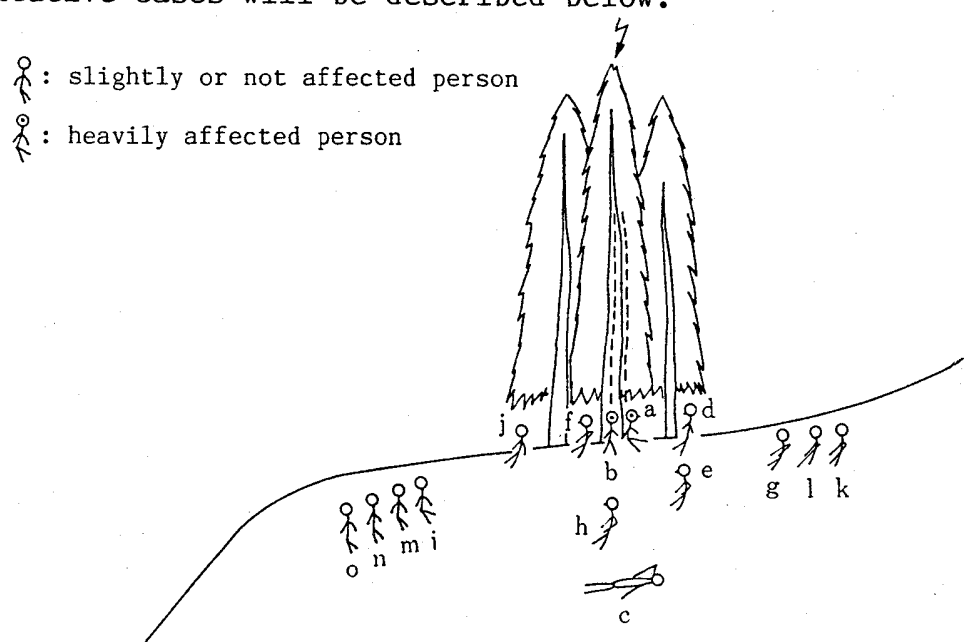

Fig. 1. Sketch of the situation of persons when a thunderbolt struck a cedar tree. injuries on them. A lying man (c) got momentary numbed feeling on the right side of his body which had touched the ground. However, the effect on him was slight and he joined rescue work, carrying one of the faint women on his back. Five persons $(k, 1, m, n, o)$ got entirely no effects. As to the rest six persons (d,e,f,g,i,j), some suffered ear ringing and others got temporal pain, numbed feeling or slight thermal injuries on their chests and arms, but none of them received injuries on lower parts of their bodies. The authors reasoned why only two persons $(h, c)$ got certain effects on the portion of their bodies which had touched the ground and the rest of persons did not. They finally reached the interpretation that one flashover 
arc had developed on the ground from the root of the tree and passed underneath of the two persons $(h, c)$. The person (c) lay almost perpendicular to a current flow-line and might have not been affected by conduction current on the ground.

Another noteworthy accident occurred during a baseball match. When a runner was sliding to reach a second base and a second baseman returned to the base, the baseman was struck by lightning and was killed almost instantly. No flashover arc along ground surface was observed. The runner lost his consciousness but recovered in a few minutes. He was taken to a hospital, received medical inspection and was diagnosed all right, except temporal tachycardia. It should be noted that at that time sky was cloudy and neither rain nor thunder were observed, though the meteorological observatory had already announced lightning warning over this area.

Golde and Lee (1976) also summarized that death caused by step voltage was rare. H. J. ten Duis et a1. (1985) interpreted in their article that two sufferers standing close to the tree struck by a lightning, were affected by step voltages. However, they must have received side flashes upon their heads from the tree, because they lost consciousness for a while. The interpretation was based on the paralysis which they suffered on their lower limbs. The present investigations indicate that persons who are situated close to struck points and get certain effect, usually suffer paralysis on their lower limbs.

Wiesinger (1975) gave mountaineers warning to avoid the danger of step voltage, but what is actually dangerous, is a flashover arc along rocky mountain surface caused by a thunderbolt. The tragic accident at NishiHotaka Peak was the worst case. A huge flashover arc along a ridge caused by a thunderbolts on the peak, killed ten boys simultaneously and threw down one boy to death (Matsumoto-Fukashi High School, 1969; Appendix of Golde and Lee, 1976). Peterson (1962) adequately analyzed the lightning injuries of mountaineers and presented many useful and practical protective measures for mountaineers. One point he could not realize is such nature of discharges that along human bodies and along ground surfaces, flashovers develop with high probability, when thunderbolts strike them. What he called "earth current" in his article, should be interpreted and termed as "surface flashover along ground surface".

As a whole, it is conclusively summarized as follows:

The conduction current on the ground caused by close thunderbolts, does not severely affect human bodies. Meanwhile, surface flashovers caused by thunderbolts, occasionally affect persons sitting or lying on their paths, raising thermal injuries or temporal paralysis. In certain specific conditions, such as on steep mountain slopes, their effects turn to crucial results.

5. Was the kneeling or squatting posture safe enough?

In four direct strike accidents, the authors could ascertain the following postures when persons were struck by 1ightning:

2: squatting down in farms and were dead,

1: dipping himself in a river up to his abdomen, fishing and was dead,

1: lowering himself on a small boat, taking fishes from a net in water and was dead.

Two persons took following low postures when they received side flashes from overhead twigs:

1: sitting down on the ground and severely suffered,

1 : sitting on a flat stone and severely suffered. 
In 53 direct and side flash accidents (36 direct and 17 side flash accidents in Table 1), each flash caused at least one dead or severely affected sufferer. Among these accidents, the percentage of those caused on squatting or similarly posturing persons amounted to $11.3 \%$. It is concluded that such postures as squatting or kneeling is not safe enough to avoid the incidence of thunderbolts on human bodies.

6 . The accidents caused by forked flashes

Occasionally a lightning channel branches in the air and strikes the ground at plural points in a course of one flash (Edano et al., 1982). A flash of this type is called a multi-points-striking flash or, simply, a forked flash.

Among 59 investigated accidents, four cases are judged to be caused flashes of this type. The objects struck by main lightning channels and the number of suffered persons are shown Table 3 .

Table 3. Number of sufferers judged to be struck by forked flashes

Location Object struck No. of suffered persons

\begin{tabular}{llrrr} 
Location & $\begin{array}{l}\text { Object struck } \\
\text { by main channel }\end{array}$ & $\begin{array}{l}\text { No. of suffered persons } \\
\text { Dead }\end{array}$ & $\begin{array}{l}\text { surily } \\
\text { Heaviight1y }\end{array}$ \\
\hline Near top of Mt.Fuji & Ground & 0 & 2 & 5 \\
Mt. Akita-Komagatake & Guidepost & 0 & 2 & 11 \\
Kani golf course & Human body & 1 & 0 & 4 \\
Ikumi seashore & Human body & 6 & 2 & 4
\end{tabular}

At Kani Golf Course one of players was instantly killed by a flash, at the same time a pine tree 30 meters apart from him, was struck by lightning and series of distinct traces of flashover arcs, were caused along its trunk. In other three cases, total number of dead and severely affected persons per flash, exceeded one and the injuries of persons classified as slightly were relatively severe compared with those of slightly affected persons in usual direct flash accidents. Though no optical records of lightning channels were obtained, it is undoubtedly deduced that they branched in the air and struck plural points including dead or severely affected persons. At Ikumi seashore, lightning accident occurred on sea where 12 persons were playing surfing. In addition to the forked lightning incidence on them, sea water drowning might have increased the number of dead victims.

7. Lightning incidents inside buildings

For recent 15 years, the authors can find no report of indoor fatal accident. The accidents which authors could investigate are only two and the effects of lightning were found to be very slight in both cases (see Table 1).

In one case of indoor incidents, a ball lightning appeared and touched an elbow of a house wife, right after a thunderbolt struck her house. No injury was observed but slight pain on her elbow lasted for about three months.

In another indoor incident, an old woman felt a spasm on her tongue at the moment when a thunderbolt struck TV antenna on her house. Thereafter she suffered slight headache for about a month.

Eriksson and Smith (1986) reported that the percentage of fatal 1ightning accidents inside huts and usual buildings were relatively high in South Africa (11\% of all accidents). In Japan, I. Kobayashi (1969) reported 
that fatal accidents inside houses used to occur relatively frequently and amounted to 20 persons for 23 years. Thus, both the frequency and the grade of the effects have drastically changed in Japan. One of the information sources which the authors used, is the report of the National Police Agency. Since the report does not miss any fatal lightning accidents, it has turned out that in Japan the inside of buildings is far safer than any outdoor protected area.

8. Features of 1ightning discharges which involve human bodies

On the basis of the research group's studies and the results of present

59 on-the-spot investigations, the features of lightning discharges on human bodies are summarized as follows:

(1) Against lightning incidence, human skin, viny1 raincoats, rubber boots and all kinds of insulators, exert no insulating effect and human bodies react as conductors of about $300 \mathrm{ohm}$ from head to foot.

(2) Surface discharges occur along human bodies with the voltage gradient of about $250 \mathrm{kV} / \mathrm{m}$. The lightning current which reaches a human head proceeds in two ways (a) as conduction current through the body and (b) as surface discharges along the body.

(3) The surface discharges along the body cause lightning marks, burns all of which are superficial thermal injuries and are easily cured.

(4) The conduction current through a human body causes cardio-respiratory arrest which usua11y results death.

(5) The metal pieces on human bodies trigger and enhance surface discharges and tend to reduce conduction current through bodies.

(6) It is not any metal pieces on a human body but the human body itself that induces lightning incidence. Objects extruding higher than head amplify the lightning-inducing effect of the human body.

(7) Staying closely to objects such as trees, tent poles, cranes etc. which are not equipped with lightning conductors, are more hazardous than standing on open field.

(8) In case of direct flash accidents, struck persons are killed or severe$1 y$ affected (fatal ones being about $80 \%$ of direct flash accidents). Mean while, the effects on closely situated persons are slight and usually need no hospital treatments.

(9) In case of side flash accidents, number of persons killed or severely affected, increases according to the number of persons situated closely to struck objects.

(10) In $6.8 \%$ of 1ightning accidents, thunderbolts strike ground at plural points including human bodies and cause plural dead or severely affected sufferers.

(11) In $11.3 \%$ of direct and side flash accidents, squatting or sitting persons are killed or severely affected. Such postures are not safe enough to avoid lightning incidence.

(12) The effect of step voltages due to close thunderbolts are slight regardless of the posture of human bodies.

(13) The surface flashovers on the ground due to thunderbolts, cause thermal injuries or temporal paralysis on human bodies sitting or lying on their paths.

9. Safety problems in lightning accidents

The inside of the Faraday cage is a safe space into which lightning discharges do not penetrate. In daily life, cars, buses, trains and reinforced concrete buildings provide such safe space. Inside wooden buildings and small huts, it is recommended to stay in a space one meter apart from 
walls, pillars and ceilings. It is also recommended, in all kinds of buildings, to stay one meter apart from power and telephone lines and from a11 electric gadgets connected to them. It is probable that lightning surges propagating along those lines, cause injuries on adjacent persons.

In view point of safety, the following items are of primary importance: (1) Death is caused on1y by the direct or side flash which causes inflow of heavy conduction current into a human body.

(2) When consciousness, respiration and pulsation of sufferers are recovered in early stage, they are saved and their injuries are cured in certain lapse of time.

(3) Removing away metal pieces from bodies does not decrease the probability of lightning incidence and the insulating effects of vinyl rain coats, rubber boots, etc. do not work at all.

(4) The probability of lightning incidence is fairly high for squatting or sitting posture (such accidents occurred in $11.3 \%$ of direct and side flash accidents).

(5) The effects of so-called step voltage are not noticeable. On the other hand, when surface flashover arcs develop on the ground from struck points, persons on their paths usually suffer burns or temporal paralysis.

(6) Direct flash or side flash accidents often occur when thunderclouds are distant and thunders are barely audible or when thunderclouds seem to have passed away.

For the safety, it should be stressed that one should first behave to avoid either direct or side flashes. Secondly, resuscitate suffers, when caused, by applying artificial respiration and external cardiac massage. So far the respiration and pulsation of sufferers are recovered, the rescue task has almost succeeded.

K. Berger's suggestion for persons in open fields (1971), (its Japanese translation was published in 1976) has to be altered. He recommended "Kneel down, with both knees and feet touching and do not lie down on the ground". However, in 59 on-the-spot investigations, six squatting or similarly posturing persons were struck by direct or side flashes, being killed or severely affected, while two persons lying on the ground in the vicinity of struck points were only slightly affected.

The value of the time intervals of thunderbolts which strike a common limited area e.g., an area within radius of 100 meters, will be effectively used to avoid lightning casualties. At present, extensive statistics are not available on this value. The authors have estimated a measure to avoid thunderbolts in following way. The time intervals of succeeding thunderbolts are about one minute for active thunderstorms. So, it can safely be estimated that when one observes a close thunderbolt, he may be free from being struck by another one for next one minute.

10. Safety guide against lightning hazards

The feature of lightning discharges on human bodies summarized in paragraph 8 and what was discussed in paragraph 9 , necessarily lead to numerous practical safety measures. Among them, essential ones are briefly stated as follows:

(1) Stay inside buildings, cars, buses, trains and huts. As a second best measure, enter and stay in protected area by tall objects or aerial power lines, namely area within vertical angle of 45 degree from their highest points. Stay in safe area until you can ascertain thunderstorms are completely over.

(2) When you are on open flat terrain, lay down on the ground all long objects such as an umbrella, a fishing rod, a golf cub, a pickel etc. Do 
not take off metal pieces you wear or carry. When you anticipate a direct bolt, lie down immediately. In usual case, lower yourself as low as possible, observe lightning activity and look around buildings or high objects which will provide protected area. When thunders are audible, move into buildings or protected area. When lighting activity is close and frequent, move toward safer area for each one minute interval, right after you notice close thunderbolts.

(3) When you intend to enter protected area of high objects, keep distance of more than two meters from them. In case of high trees, keep at least two meters from a11 twigs and leaves. In any case, lower yourself by all means.

(4) When you find faint persons, check their pulse and respiration. In case they are arrested, resuscitate them by applying artificial respiration and external cardiac massage. You may learn the methods on the video-tape published by Maruzen (1989), Tokyo .

(5) When you intend to go out for outdoor work or recreation, observe carefully weather forecasts and arrange your plan so that you will not be caught by thunderstorms.

Acknowledgments. The authors express their sincere thanks to the members of the research group, Dr. S. Turumi, Tokyo Science University, Dr. K. Takagi, Kisarazu College of Technology and Dr. Y. Nagai, Shonan Institute of Technology for their cooperation in laboratory experiments.

\section{References}

Berger, K., Suggestions for the protection of persons and groups of persons against lightning hazards, WMO Report of International Commission on Atmospheric Electricity (IAMAP/IAGA, UGGI, ICSU), 1971. Japanese translation was published as Hirai-Kokoroe, Taiki-Denki-Kenkyu, special issue, 1976.

Duis, H. J. ten, H. J. Klasen and P. E. Reenalda, Keraunoparalysis, a 'specific' 1ightning injury, Burns, 12, 54-57, 1985.

Edano, Y, Y. Nagai, and S. Kawamata, Observation of simultaneous-bi-stroke flashes, Res. Lett. Atmos. Electr., 2, 49-52, 1982 (in Japanese).

Eriksson, A. J and M. A. Smith, A study of lightning fatalities and related incidents in South Africa, Trans., SAIEE, 163-174, November, 1986.

Golde R. H. and.W. A. Lee, Death by lightning, Proc., IEE, 123 , No.10R, 1163-1180, 1976.

Kitagawa, N., S. Turumi, T. Ishikawa and M. Ohashi, The nature of 1ightning discharges on human bodies and the basis for safety and protection, Proceedings of 18th ICLP, VDE-VERLAG GmbH, Ber1in, 435-438, 1985.

Kobayashi, I., Two problems in 1ightning protection, Densetsu-Kogyo, MarchIssue, 5-15, 1969 (in Japanese).

Maruzen, How to App1y Cardiac and Respiratory Resuscitation, Video-tape in Japanese, Maruzen, Nihon-bashi, Tokyo, 1989.

Matsumoto-Fukashi High Schoo1, Report on Lightning Disaster at Nishi-Hotaka Peak, Matsumoto-Fukashi High Schoo1, Matsumoto-shi, 1969 (in Japanese). English summary appeared as Appendix of the paper by Golde and Lee, 1976.

Peterson, A. E., Lightning hazards to mountaineers, American Alpine Journal, 1962. Japanese translation appeared in "Iwa to Yuki", No.10, Yama-To-Keikoku-Sha, 1967.

Wiesinger, Von J., B1itzgefahren und B1itzschutz im Gebirge, Zeitschrift für Allgemeinmedizin, Heft 5, 265-268, 1976.

(Received Apri1, 12, 1990; Revised May 18, 1990; Accepted June 1, 1990.) 